\title{
IoT Based Smart Solar Flower Water Pump System
}

\author{
Prof B H Band ${ }^{1 *}$, Prof A D Ingole ${ }^{2}$ \\ 1: Assistant Professor, Electrical Engineering Department, PRMCEAM, Badnera, Maharashtra, India \\ 2: Assistant Professor, Electronics and Tele-communication Engineering Department, PRMCEAM, \\ Badnera, Maharashtra, India
}

Received June 11, 2019; Accepted July 18, 2019; Published July 26, 2019

\begin{abstract}
The electric demand of the countries is increasing day by day and the available resources are quite insufficient to fulfill this demand. The reasons are that the conventional energy resources are diminishing and available with finite sources. Due to these reasons, the solar power is one of the promising alternatives that is easily available, pollution free and having higher operating life. The solar system also provides higher operating efficiency for the load, and the cost of the solar panel is minimum. To improve the switching technology used for the power conversion, we presented a smart flower system powered by photovoltaic panels that could supply standalone AC/DC load. In this system, solar panels produce a direct current, which can be converted into $\mathrm{AC}$ by the converter and used in home, industrial and agriculture applications. The output of the panels depends on the direction of sun's rays (solar energy), and the solar photovoltaic cell converts the solar energy into useful electrical energy. The aim of this paper is to develop the solar photovoltaic generation system based on a standard power electronics cell for micro industrial, commercial, home as well as agriculture applications. The proposed system is capable to provide protection from wind and rain, thereby the efficiency of the solar panels will increase. The generation of the electricity is more with trackers than stationary counterparts due to direct exposure to sun's rays. This increase can be as much as $25 \%$ depending upon the geographic location of the tracking system. The generated output voltage can be used for various purposes, and we used the store energy to run an agriculture water pump by using the internet of things (IOT).
\end{abstract}

Keywords: Solar Flower; Energy Generation; IoT; Water Pump; Motor; Solar Tracker

\section{Introduction}

The smart flower was named after its design, in which the solar cells are arranged on individual "petals" that open at the beginning of each day and look like a flower (https://news.energysage.com/smartflower-solar-complete-review/). After the sun sets, the petals of the smart flower fold up and the self-cleaning process begins. The smart flower system includes a dual-axis tracker that allows the petals to follow the sun through the sky throughout the day. According to smart flower's survey, with this tracking feature, the smart flower system can generate $40 \%$ more electricity than a rooftop solar panel system of the same size. The smart flower system has the same solar power benefits as a regular solar system, as well as an integrated battery that provides more energy storage. 
It has been more than fifteen years since the term of Internet of Things (IoT) was introduced to the public. It is basically used to connect living and non living things with each other through the internet. IoT allows people and things to be connected anytime, anyplace, with anything and anyone, by using ideally in any path/network and any service.

As the non-renewable energy resources are decreasing, the use of renewable resources for producing electricity is increasing. Solar panel absorbs the energy from the Sun, converts it into electrical energy and stores the energy in a battery. This energy can be utilized when required or can be used as a direct alternative to the grid supply. The energy stored in batteries can be utilized for the agriculture pump. The coming sun's rays is varying in different directions due to the rotation of the Earth. For an efficient usage of the solar energy, the solar panels should absorb energy to a maximum extent. This can be done only if the panels are continuously placed towards the direction of the Sun. So, solar panels should continuously rotate in the direction of sun as we are introducing the smart flower with it.

\section{Literature Review}

In recent year, the solar energy system is one of the most popular things for the homes and also for the business in India. Believe it or not, this desire to use the Sun to power people's electricity needs is anything but new. Ever since scientists discovered materials that can produce the electrical current by simply being exposed to the light, people have been excited about this energy source. This article outlines the details of solar power generation and the expanding world.

The operating principles for modern photovoltaic (PV) cells were first discovered in 1839 by a French physicist named A.E. Becquerel. After that, a number of scientists played with and improved on Becquerel's original discovery. This technology soon found its way back down to earth for use in telecommunications applications in remote areas. People began using PV modules to charge batteries from the year 1970s and 1980s and then used these batteries to run various appliances in their remote homes. These discoveries help the people in today's environment $[1,2]$.

The first PV module isn't sufficient for various applications. They were also quite costly. Yet over the years, researchers and manufacturing companies increased efficiencies and reliability and managed to drive down costs drastically. All of these contributions have led to the widespread use of solar modules and their availability to you and me. In the following sections, we describe some common PV applications, a few brief pros and cons of PV systems, and the future of the PV industry.

The improvement in the PV systems can be found in a wide variety of applications, such as the power calculators, pump water, help offset the energy used by floodlights along highways, and, of course, power homes and businesses [3, 4].

The smart flower at the University of Applied Sciences Kufstein (FH Kufstein, Austria), also known as the 'FH smart flower', fulfills multiple purposes. The power generated from the FH smart flower is fed into the school's electrical grid and is also used as a tool for teaching in the discipline of applied energy data management. Its location in the city park makes it not only an eye catcher for employees and tourists, but also a catalyst for conversation about photo voltaic between students of all disciplines and their peers in the energy management program (https://www.pfisterenergy.com/ 
smartflower/). The smart flower has several photovoltaic panels that fan out like the petals of a flower during the day to capture energy from the Sun. Since solar panels are more efficient when they are pointed directly at the Sun, the smart flower tracks the sun east to west and up and down all day to provide the maximum possible energy from the available sunlight [5-7].

The cost of the solar system is always a concern to the public. The best way to compare solar panel system prices is to determine the cost per watt of electricity generation. The installed cost depends on distance of the installed smart flower from the home, whether a concrete slab foundation needs to be poured, and whether the installation requires additional electrical work. By comparison, the median price for a standard ground-mounted solar energy system without tracking capabilities on the Energy Sage Solar Marketplace was just $\$ 3.43 / \mathrm{Watt}$, or $\$ 13,720$ for a $4 \mathrm{~kW}$ system $[8,9]$.

In the literature of [10-12], the review report provided in this paper provides the best choice for a variety of technologies and agricultural pumps that can be used in pump systems. In other papers, it explains the applicability of motors to pump systems.

\section{Proposed System}

The design of the solar tracker system can be classified into three sections (Figure 1). There is the input stage that is composed of sensors and potentiometers, a program in embedded software in the microcontroller and lastly the driving circuit that has the servo motor. The input stage considers with two light dependent resistors (LDR) and that are assembled to form a voltage divider circuit. A ' $\mathrm{C}$ ' program loaded into the Atmega328P microcontroller forms the embedded software. The all components are mounted in the metallic frame. The three stages are designed independently before being joined into one system. This approach similar to stepwise refinement in modular programming has been employed as it ensures an accurate and logical approach which is straight forward and easy to understand. This also ensures that if there are any errors, they are independently considered and corrected.

The main purpose to write the paper is to satisfy two main objectives:

- Design a solar system which can track the solar UV light for solar panels through the day.

- Design a tracking system for the solar panel to increase the efficiency of the system than the ordinary solar system.

The system is designed so that the sun's rays fall vertically on the solar panels to get the most solar energy. This is harnessed into the electrical power. Maximum energy is obtained between $1200 \mathrm{~h}$ and $1400 \mathrm{~h}$, with the peak being around midday. At this time, the sun is directly overhead. At the same time, the least energy will be required to move the panel, which will further increase the system efficiency. The system is designed to address the challenge of low power, accurate and economical microcontroller-based tracking system which is implemented within the allocated time and with the available resources. It is supposed to track the sun's movement in the sky. In order to save power, it is supposed to sleep during the night by getting back into a horizontal position. There is implementation of an algorithm that solves the motor control that is then written into $\mathrm{C}$ program.

The main supply is fed to the load under normal conditions. When the main supply gets shut down, the supply from the battery connected to the system will be fed to 
the load to fulfill the desired output. The battery is switched to the circuit by switching the relay. The main part of the system is that we are using two sources for charging the battery.

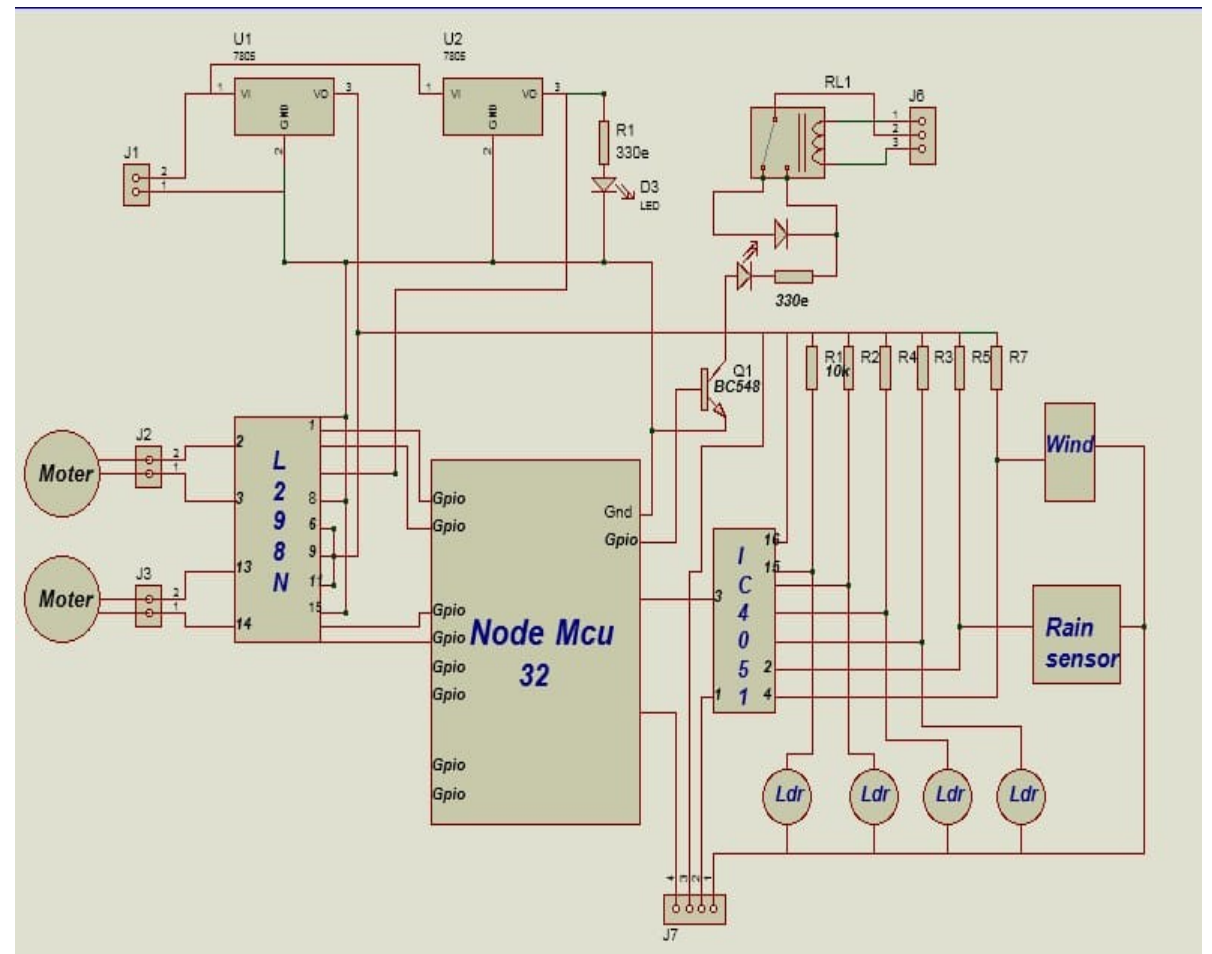

Figure 1. Designed circuit

The main supply is coming from the distribution board and the other is a power generated from the solar panel of the smart solar flower. Priority of a charging is given to the solar panel, i.e., when the solar power generated exceeds the desired limit, it comes into the supply to get battery charged. The output voltage of the solar panel is kept at 12 $\mathrm{V}$ and is compared with the main voltage supply. When the solar panel voltage goes beyond $12 \mathrm{~V}$, the battery starts charging on a solar energy. Transformer is used to step down the AC voltage $230 \mathrm{~V} / 12-0-12 \mathrm{~V}$. It is fed to the rectifier circuit which converts $\mathrm{AC}$ to pulsating DC. Further pulsating DC is made pure by connecting the filter in the circuit. Five V DC is fed to the Node MCU $32 \mathrm{~S}$ and relay driving circuit. Relay switches the operations as per the instructions are given in the microcontroller ATmega328p programming. According to the relay, the motor will operate (Figure 2).

Here, we used a rain water sensor, which is connected in the circuit via two wires. One is from ground and the other is from the microcontroller's logic pin. Initially, logic is 1. But when water falls on chip, the logic will be zero and hence the flower will close. We also used a soil moisture sensor, in which initially there is logic 1 and when the logic became 0 , the pump will operate. The relay used for switching purpose is electromagnetic in nature and the switching operation of the relay is performed by the controller. 


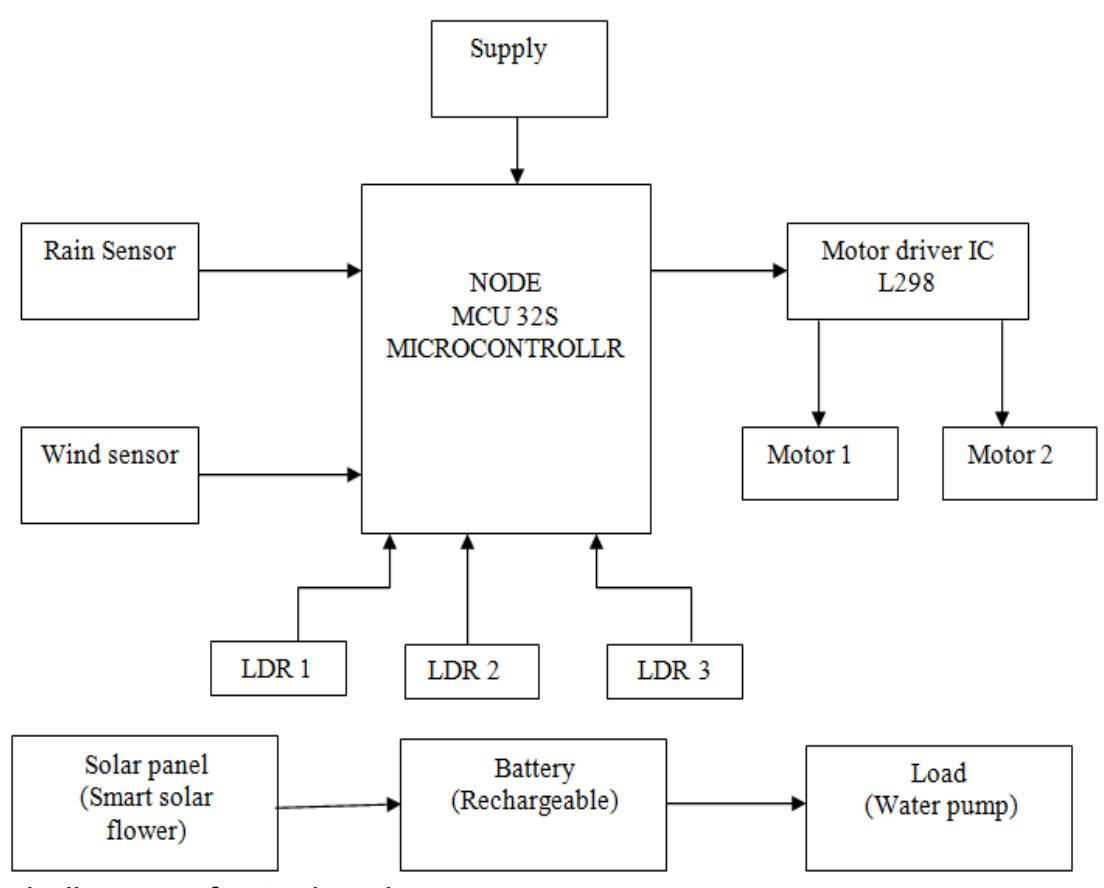

Figure 2. Block diagram of actual work

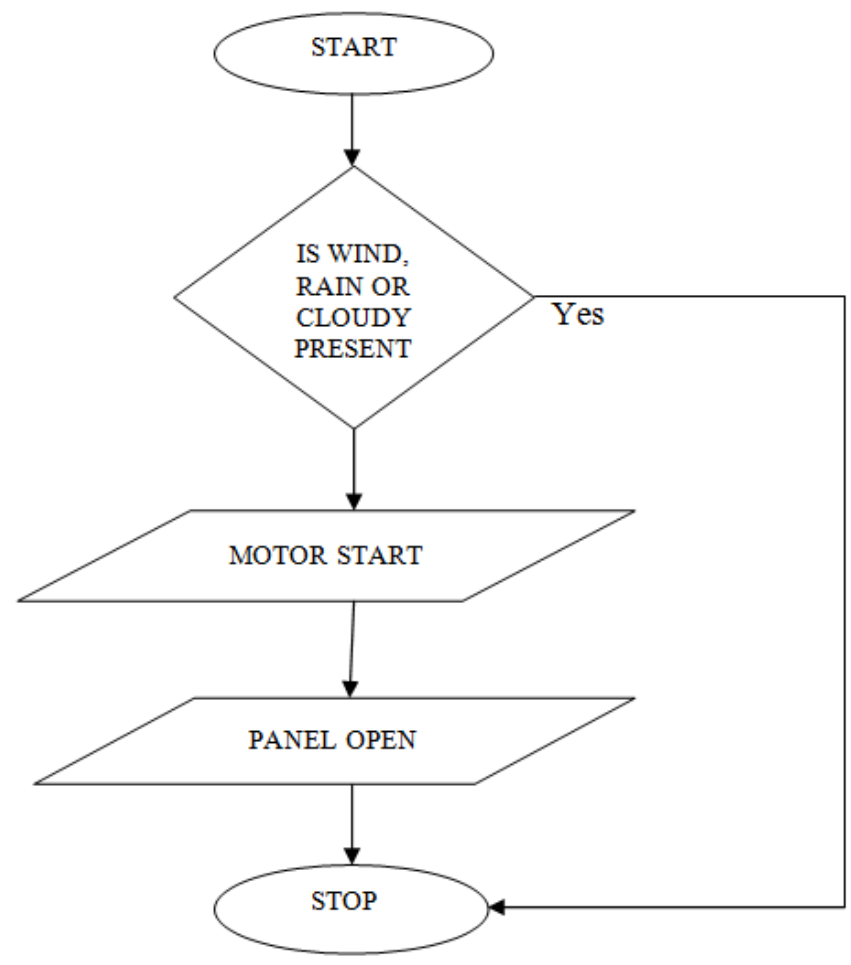

Figure 3. Working flowchart

The solar panel voltage is monitored by the microcontroller through an analog-todigital (A/D) converter. The microcontroller is the main control core and adjusts the stepper motor so that the platform is optimally located for efficient electricity generation.

The system receives the sunlight onto the Light Dependent Resistor (LDR), where the LDR acts as the solar direction tracking sensor. The position of the LDR is obtained 
when the two LDRs having the same light intensity. In the morning time, the right side LDR is turned on (as the small resistance is nearly shorted), which causes a signal to turn the motor to continuously move in clockwise until the two LDRs getting the same light intensity again. As the day slowly progresses, the left LDR is turned on and the motor turns counter clockwise. The cycle continues until the end of the day, or until the minimum detectable light level is reached. Figure 3 shows that when the sun is at the right to the solar panel, the right LDR has small value resistance, the left LDR has no light (large resistance), and the software in the micro-controller translates this to signals to control the stepper motor to rotate the panel to the right. There is a reset button for positioning the panel to an initial position which is at an inclination of 40 degrees. This is done preferably in the evening after the sun has set. It makes the LDR go back to an initial position, ready for tracking the sunlight on the next day. There is also a push button for initializing the servo motor. It switches it on, leaving it on standby mode. Pins number 7, 20 and 21 are used for powering the microcontroller. It requires $5 \mathrm{~V}$. The inputs to the LDR are simulated.

The proposed model of the solar flower system is shown in Figure 4.

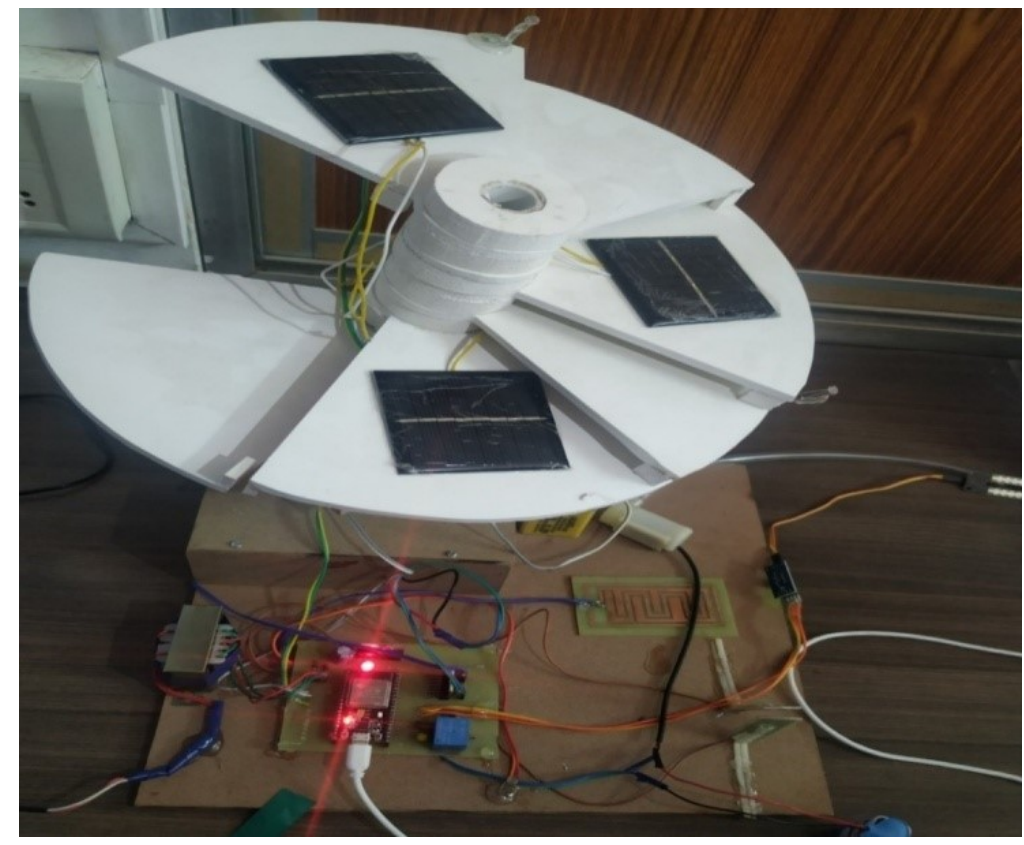

Figure 4. Proposed model

\section{Results}

We have gained the result that the system is more efficient as it includes the dualaxis solar tracking principle in it. Also, the system is smarter and safer as it contains the sensors such as wind sensor, soil moisture sensor, rainwater sensor and LDRs. Therefore, whenever there is a high wind or high raining, the solar flower unfolds its petals and hence protects the system from sudden damage. Since the IoT is used in this project, the project is usable in the remote areas. Due to the use of the soil moisture sensor, we could turn on or off the water pump. Here, it is a smarter energy management system with 
strategy and planning based on real-time data collection and processing. This technology gave a high-tech makeover to the agriculture industry.

Advantages and disadvantages of this system include:

Advantages:

- Size of the system is small.

- System has a dual-axis tracking technology which helps in maximizing the solar energy absorption by continuously tracking the sun.

- No fuel burning in this system and therefore any pollution.

- The maintenance cost is very low.

- Because the use of solar energy is not limited, it can be used for longer period of time.

Disadvantage

- Cost of system is very high.

- The system is complex due to the batteries and motors. They are heavy and occupy more space and require time to time maintenance.

\section{CONCLUSIONS}

The system was designed for the benefits of various users and farmers. By using the IoT based irrigation system, it optimizes the usage of water by reducing wastage and human efforts. Proposed system is easy to implement and environment friendly solution for irrigating fields. The system was found to be successful when implemented for bore holes as they pump over the whole day. Solar pumps offer clean solutions with no danger of borehole contamination. The system has no maintenance and it also self-starting. The system can be used with application to provide energy for the pumping requirements for sprinkler irrigation. Even though there is a high capital investment required for this system to be implemented, the overall benefits are high and in long run this system is economical.

\section{CONFLICTS OF INTEREST}

The authors declare that there is no conflict of interests regarding the publication of this paper.

\section{REFERENCES}

[1] Kabalci, E., Gorgun, A., and Kabalci, Y. Design and implementation of a renewable energy monitoring system. In: Proc., 4th International Conference on Power Engineering, Energy and Electrical Drives, pp: 1071-1075. DOI: 10.1109/PowerEng.2013.6635759

[2] Jiju, K., Ramesh, P., Brijesh, P., Sreekumari, B. Development of Android based online monitoring and control system for Renewable Energy Sources. In: Proc., 2014 International Conference on Computer, Communications, and Control Technology (I4CT), pp: 372-375. DOI: 10.1109/i4ct.2014.6914208 
[3] Souza, A. M. C., and Amazonas, J. R. A. A Novel Smart Home Application Using an Internet of Things Middleware. In: Proc., Smart SysTech 2013; European Conference on Smart Objects, Systems and Technologies, pp: 1-7.

[4] Kelly, S. D. T., Suryadevara, N. K., and Mukhopadhyay, S. C. (2013). Towards the Implementation of IoT for Environmental Condition Monitoring in Homes. IEEE Sensors Journal, 13(10), 3846-3853. DOI: 10.1109/jsen.2013.2263379

[5] Iera, A., Floerkemeier, C., Mitsugi, J., and Morabito, G. (2010). The Internet of things [Guest Editorial]. IEEE Wireless Communications, 17(6), 8-9. DOI:

$10.1109 / \mathrm{mwc} .2010 .5675772$

[6] Bikash, D. Solar powered lighting and ventilation of poultry house. MS thesis, Mymensingh: Bangladesh Agricultural University, Department of Farm Power and Machinery, Vol.19, March 2014.

[7] Roblin, S. (2016). Solar-powered irrigation: A solution to water management in agriculture? Renewable Energy Focus, 17(5), 205-206. DOI: 10.1016/j.ref.2016.08.013

[8] Hussain, M. I., and Lee, G. H. (2015). Utilization of solar energy in agricultural machinery engineering: A review. Journal of Biosystems Engineering, 40(3), 186-192.

[9] Jie, Y., Pei, J. Y., Jun, L., Yun, G., and Wei, X. Smart Home System Based on IOT Technologies. In: Proc., 2013 International Conference on Computational and Information Sciences, pp: 1789-1791. DOI: 10.1109/iccis.2013.468

[10] Band, B.H., Ingole, A.D. IOT and GSM based solar operated water pump system: a technical review. INTERNATIONAL JOURNAL OF CURRENT ENGINEERING AND SCIENTIFIC RESEARCH (IJCESR), Volume 6, issue 3, 2019, pp: 170-172. [11] Band, B.H., Ingole, A.D. Mathematical and Simulation Approach for Synchronization of Two Asynchronous Grids. INTERNATIONAL JOURNAL OF ENGINEERING RESEARCH \& TECHNOLOGY (IJERT), Volume 7, issue 9, Sept-18, pp: 24-27

[12] Band, B.H., Ingole, A.D. Transfer of Power by using two Induction Machines. INTERNATIONAL JOURNAL OF CURRENT ENGINEERING AND SCIENTIFIC RESEARCH (IJCESR), Volume 4, issue 8, 2017, pp: 36-40

Article copyright: (C) 2019 B H Band, A D Ingole. This is an open access article distributed under the terms of the Creative Commons Attribution 4.0 International License, which permits unrestricted use and distribution provided the original author and source are credited. 